\title{
The Effect of Ocean Dynamics and Orography on Atmospheric Storm Tracks
}

\author{
CHRIS WILSON \\ Proudman Oceanographic Laboratory, and Department of Earth and Ocean Sciences, University of \\ Liverpool, Liverpool, United Kingdom \\ BABLU SINHA \\ National Oceanography Centre, Southampton, United Kingdom \\ RICHARD G. WILLIAMS \\ Department of Earth and Ocean Sciences, University of Liverpool, Liverpool, United Kingdom
}

(Manuscript received 2 June 2008, in final form 5 December 2008)

\begin{abstract}
The control of atmospheric storm tracks by ocean dynamics, orography, and their interaction is investigated using idealized experiments with a simplified coupled atmosphere-ocean climate model. The study focuses on the quasi-steady state for the storm tracks in the Northern Hemisphere winter mean. The experiments start with a background state without mountains and ocean dynamics, and in separate stages include orography and a dynamic ocean to obtain a more realistic control simulation. The separate effects of ocean dynamics, orography, and their nonlinear interaction are identified for the storm tracks and the surface thermodynamic forcing over the ocean.

The model study suggests that atmospheric storm tracks are a robust feature of the climate system, occurring at midlatitudes even if there is no orographic forcing or ocean heat transport. Ocean dynamics generally lead to a poleward shift in both the storm track and the maximum in atmospheric northward heat transport and induce a northeastward tilt over the Atlantic. This poleward shift is linked to the extra heat transport by the ocean and the tightening of sea surface temperature gradients on the western side of ocean basins. Orographic forcing causes along-track variability with a weakening of the storm track over the continents and induces a northeastward tilt over the western Pacific, which is associated with a stationary planetary wave train generated by the Tibetan Plateau. The interaction between ocean dynamics and orographic forcing plays a localized role, enhancing the contrast between the Atlantic and Pacific. Much of the response to the forcing is eddy mediated and transient eddies help to spread the influence of orographic and ocean forcing.
\end{abstract}

\section{Introduction}

Atmospheric storm tracks occur at midlatitudes, predominantly over the western part of ocean basins, as revealed in enhanced synoptic-scale bandpass-filtered variance (Fig. 1a), and are linked to the strong westerly jets in the troposphere and stratosphere (Blackmon et al. 1977; Hoskins and Valdes 1990; Chang et al. 2002). The storm tracks are associated with the life cycle of synoptic-scale eddies, which amplify as they pass along the storm track

Corresponding author address: Dr. Chris Wilson, Proudman Oceanographic Laboratory, 6 Brownlow Street, Liverpool, L3 5DA, United Kingdom.

E-mail: cwi@pol.ac.uk and eventually decay downstream (Hoskins et al. 1983; Hoskins and Hodges 2002, 2005). There is an ongoing debate as to how storm tracks are controlled, particularly in terms of how their structure deviates from zonal symmetry and how they vary along track.

A mechanism is needed to maintain storm tracks because synoptic-scale eddies locally reduce the baroclinicity from which they draw their energy. Hoskins and Valdes (1990) proposed that storm tracks are maintained by surface heating from the ocean through the heat supplied by warm western boundary currents. In contrast, orography is widely viewed as controlling the stationary planetary wave pattern (Nigam et al. 1988; Seager et al. 2002), which provides a waveguide for stormtrack eddies (Chang et al. 2002). In addition, Seager 
a) Sqrt(High-pass EKE): ERA-40 (shaded) and model (contours)

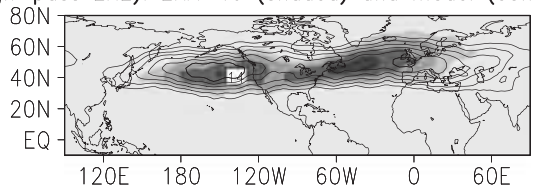

b) Sqrt(High-pass EKE) bias: Model - ERA-40

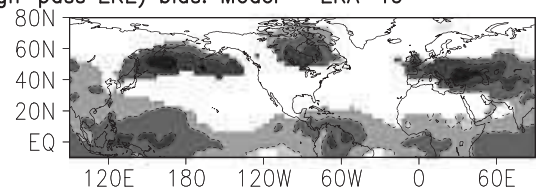

c) High-pass [ [v'T']: ERA-40 (shaded) and model (contours)

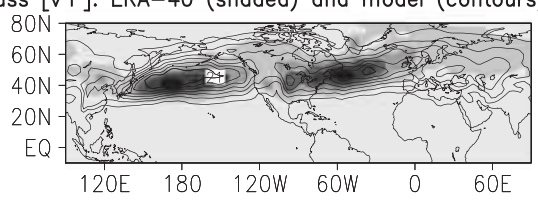

d) High-pass [ $\left.v^{\prime} T^{\prime}\right]$ bias: Model - ERA-40

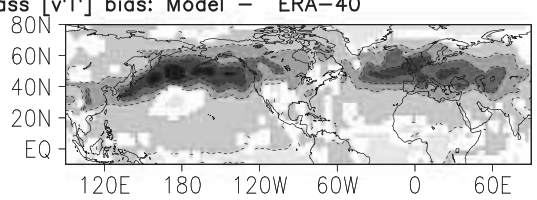

e) SST: ERA-40 (shaded) and model (contours)

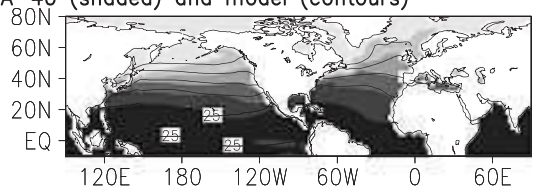

f) SST bias: Model - ERA-40

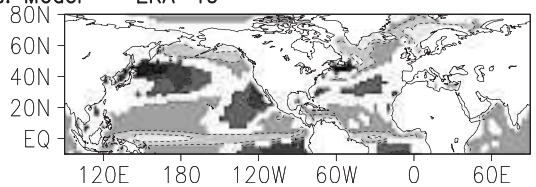

FIG. 1. ERA-40 and FORTE model climatologies and biases for a 10-yr winter mean (1992-2002 for ERA-40). (a) The square root of 250-mb high-pass EKE for ERA-40 (shaded, $\mathrm{m} \mathrm{s}^{-1}$ ), with model equivalent overlaid (contours, $\mathrm{m} \mathrm{s}^{-1}$, contour interval of 1 ). (b) Model bias for the square root of 250-mb high-pass EKE (shaded at the $95 \%$ significance level, $\mathrm{m} \mathrm{s}^{-1}$ ). (c) ERA-40 756-mb high-pass $\overline{v^{\prime} T^{\prime}}$ (shaded, $\mathrm{m} \mathrm{s}^{-1} \mathrm{~K}$ ), with model equivalent overlaid (contours, $\mathrm{m} \mathrm{s}^{-1} \mathrm{~K}$, contour interval of 3). (d) Model bias for $\overline{v^{\prime} T^{\prime}}$ (shaded, $\mathrm{m} \mathrm{s}^{-1} \mathrm{~K}$ ). (e) ERA-40 SST (shaded, ${ }^{\circ} \mathrm{C}$ ), with model SST overlaid (contours, ${ }^{\circ} \mathrm{C}$, contour interval of 5). (f) Model bias for SST (shaded, ${ }^{\circ} \mathrm{C}$ ).

et al. (2002) argue that ocean heat transport only plays a minor role in controlling the midlatitude air temperature contrast across the North Atlantic. Partly reconciling these views, Held et al. (2002) argue that both surface heating and orography are important in determining the stationary wave pattern and, by implication, the storm tracks. The intrinsic connection between stationary planetary jets and storm tracks is also, possibly, linked to nonlocal forcing and organization of eddy mixing, such as has been invoked to explain zonal jets on gas giants, such as Jupiter and Saturn, where eddy mixing is inhibited through the formation of a "potential vorticity staircase" (Baldwin et al. 2007).

In this study, the roles of ocean dynamics, orography, and their possible interaction are explored in terms of their effect on storm tracks in the Northern Hemisphere winter, as well as their modification of the surface thermodynamics. Four experiments are performed with a coupled atmosphere-ocean general circulation model with intermediate complexity; the experiments either switch orographic forcing on or off, by having orography or flat continents of 1-m height, and either switch ocean dynamics on or off, by having a fully dynamic ocean or a slab ocean consisting of a 30-m-thick mixed layer. The model experiments are described in section 2 . The separate mechanisms forcing the storm tracks and modifying the surface thermodynamics are diagnosed from the differences between the model experiments in section 3 , and the implications are discussed in section 4 .

\section{Coupled climate model experiments}

\section{a. Description of numerical model and four climate experiments}

The Fast Ocean Rapid Troposphere Experiment (FORTE) coupled climate model consists of a 15-sigmalevel, T42 horizontal resolution spectral atmosphere (Forster et al. 2000), coupled to a 15-level Cartesian coordinate, $2^{\circ}$ horizontal resolution ocean (Webb 1996), with a simple thermodynamic sea ice model and ocean eddy parameterization scheme (see the appendix; see also Sinha and Smith 2002; Smith 2004; Blaker et al. 2006). The model has a stable climate and does not need flux adjustment. The storm tracks are reasonably well resolved and the ocean resolution is sufficient to include gyre circulations with western boundary currents (although it is insufficient to resolve their extension into the gyre interior).

\section{b. Model verification}

As should be expected from an intermediate-complexity coupled model, model biases are present (Fig. 1). Stormtrack eddy kinetic energy (EKE) is slightly too strong in the core; the track is too broad in the north and extends too far into Europe (Figs. 1a,b). This bias is present in many other models (Black and Dole 2000) and may be related to deficiencies in the planetary mean flow. In our case, we believe it is related to a bias toward too-weak zonal stretching deformation in the Atlantic jet exit. The 756-mb high-pass northward eddy temperature flux is also too intense in the model (Figs. 1c,d) and extends too far north and into Europe. The intensification of the storm track is probably related to midlatitude SST bias 
because of poor resolution of the western boundary current extension. While the broad pattern of SST is similar to the climatology (Fig. 1e), the SST bias (Fig. 1f) suggests an intensification of the meridional SST gradient around $50^{\circ} \mathrm{N}$, which is consistent with a strengthening in lower-level baroclinicity at the Pacific and Atlantic stormtrack entrances. There is also an overly intense equatorial Pacific cold tongue (Fig. 1f), which is a common problem in climate models with a coarse-resolution ocean component.

Despite these caveats, it is a testament to the core physics of the FORTE model that it produces such a stable and reasonable climate, despite being less complex than the current state-of-the-art coupled climate models. For example, Winton (2003) finds that a similar slab ocean model freezes over into a snowball Earth state. The main difference is that our model uses a simple thermodynamic sea ice parameterization scheme, rather than a dynamic scheme. Winton (2003) also demonstrates that the same model has a stable climate when a simple thermodynamic sea ice parameterization scheme is used. Both Winton (2003) and Medeiros et al. (2008) additionally discuss the sensitivity of climate models to cloud parameterization schemes. These are two areas of uncertainty that may indeed have general implications for the robustness of climate model results. Although the FORTE model biases are, in certain regions, larger than the forcing response, the general structure of the large-scale fields and storm tracks are satisfactory, because we are concerned mostly with the first-order structural changes and responses in our idealized experiments. For such experiments a fullcomplexity coupled climate model (which also contains biases) is unsuitable because of the computational expense, and the FORTE model provides a useful efficient compromise.

\section{c. Idealized model experiments}

The aim of these experiments is to determine the linear and nonlinear effects of forcing from ocean dynamics and orography on the storm track. The four experiments are as follows:

1) a run without mountains and with a 30-m-deep, static mixed layer (slab) ocean referred to as the "ground state" (RUN-OC-M);

2) a run without mountains and with a fully dynamic ocean $(\mathrm{RUN}+\mathrm{OC}-\mathrm{M})$

3) a run with mountains and with a 30-m-deep, static mixed layer ocean $(\mathrm{RUN}-\mathrm{OC}+\mathrm{M})$; and

4) a run with mountains and a dynamic ocean referred to as the control state, which is viewed as the most realistic case $(\mathrm{RUN}+\mathrm{OC}+\mathrm{M})$
The focus of the experiments is to understand the background quasi-steady state, rather than the interannual or decadal variability. Hence, the runs with ocean dynamics are spun up for $90 \mathrm{yr}$ and the slab ocean runs are spun up for $10 \mathrm{yr}$, with a subsequent $10 \mathrm{yr}$ of each being diagnosed. The slab ocean also has $2^{\circ}$ horizontal resolution, and it is similar in many respects to the 50-m-deep slab version of the Hadley Centre Slab Model, version 3 (HadSM3), which is used in the Climate Prediction.net (online at http://www.climateprediction. net/) experiments (e.g., Stainforth et al. 2005). The equilibration of the four runs is shown by time series of global-mean sea surface temperature (Fig. 4, bottom). This illustrates that neither the atmosphere nor the ocean are drifting, and that the slab ocean is able to store sufficient heat. It is a testament to the model core physics and parameterization schemes that the climate does not drift even though there is no flux correction. Because we are most concerned with the storm-track response on short time scales, our intention is to spin up the upper ocean, rather than the deep meridional overturning circulation. The latter would take several millennia to equilibrate and is therefore prohibitively expensive for this study, as is the case for the majority of OGCM studies.

As a starting point, consider proxies used to identify storm tracks, high-pass-filtered EKE at $250 \mathrm{mb}$ and the Eady growth rate at $756 \mathrm{mb}$, measuring the baroclinicity of the lower atmosphere (Hoskins and Valdes 1990). In the winter mean [December-February (DJF)] of the ground-state experiment with no mountains or ocean dynamics, there is enhanced atmospheric variability over a midlatitude band and with local maxima in baroclinicity over the oceans (RUN-OC-M); see Figs. 2b, 3b. Hence, there is a midlatitude storm track with atmospheric eddies growing through baroclinic instability over the North Pacific, crossing North America without significant decay, but weakening as they cross the wider combined landmasses of Europe and Asia (Figs. $2 \mathrm{~b}, 3 \mathrm{~b})$.

Given that there are no mountains or ocean dynamics in this integration, the enhanced eddy variability in the midlatitudes probably reflects how upper-air moving poleward in the Hadley cell is deflected into fast-moving zonal jets (through angular momentum conservation). The baroclinicity in these jets is then enhanced over the warm, moist oceans and weakened over the land.

The storm track becomes more realistic as both ocean dynamics and orography are included, becoming sharper, less zonal, and acquiring more along-track variability: the storm tracks in the control run $(\mathrm{RUN}+\mathrm{OC}+\mathrm{M}$, Fig. 2a) are the closest to the observational diagnostics (Fig. 1a). 


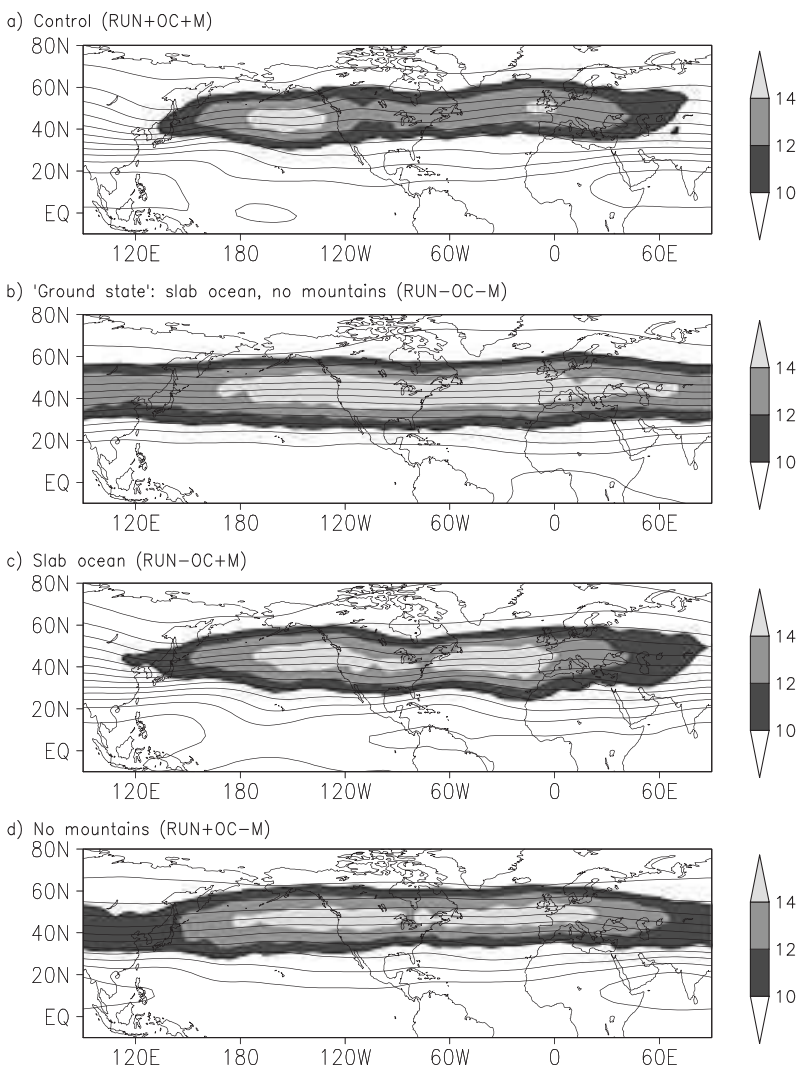

FIG. 2. The Northern Hemisphere winter-mean tracks [square toot of 250-mb high-pass EKE $\left(\mathrm{m} \mathrm{s}^{-1}\right)$, shaded] and mean flow (250-mb streamfunction, contour interval of $1.5 \times 10^{7} \mathrm{~m}^{2} \mathrm{~s}^{-1}$ ) for the last 10 winters of each of the four model integrations. (a) RUN $+\mathrm{OC}+\mathrm{M}$, the control run, has broadly similar storm tracks to ERA-40, as shown in Fig. 1a. (b) By removing both ocean advection and orography, as shown in RUN-OC-M, the mean flow is almost zonal and the storm track is much stronger that the control. The only source of the sizeable zonal asymmetry is the distribution of the (flat) continents. (c) By removing ocean advection and retaining orography, as shown in $\mathrm{RUN}-\mathrm{OC}+\mathrm{M}$, which has a slab ocean, the mean flow is almost unaltered from the control, but the storm track becomes stronger. (d) By removing orography and retaining ocean dynamics, as shown in RUN+ $\mathrm{OC}-\mathrm{M}$, the mean flow becomes much more zonal, as does the storm track. The storm track is also slightly stronger than the control.

\section{d. Calculation of the forcing components and interaction}

The separate effects of ocean dynamics, orography, and their interaction on the storm track are now diagnosed from the differences within the set of model experiments. Consider a general diagnostic variable $X$, such as eddy kinetic energy, for each of the four experiments (Fig. 4, top): $X$ in the ground state run without mountains or ocean dynamics is denoted by $X_{-\mathrm{OC}-M}$ and $X$ in the control run by $X_{+\mathrm{OC}+M}$, with a) Control $(\mathrm{RUN}+\mathrm{OC}+\mathrm{M})$

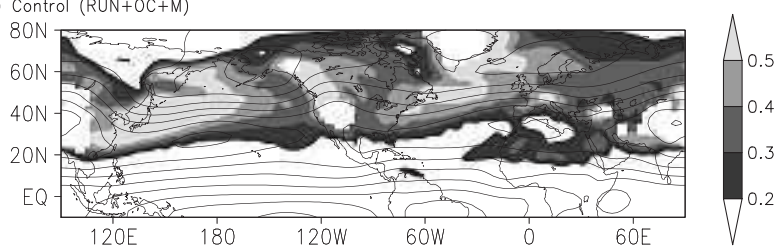

b) 'Ground state': slab ocean, no mountains (RUN-OC-M)

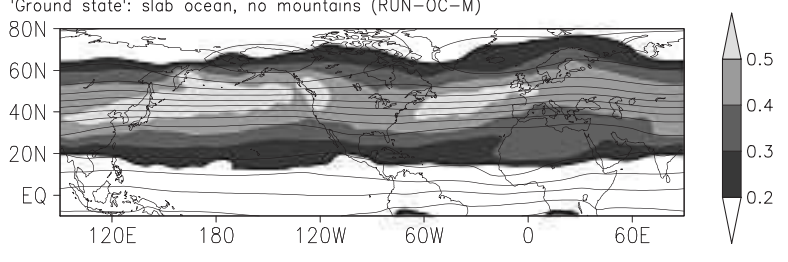

c) Slab ocean (RUN-OC+M)

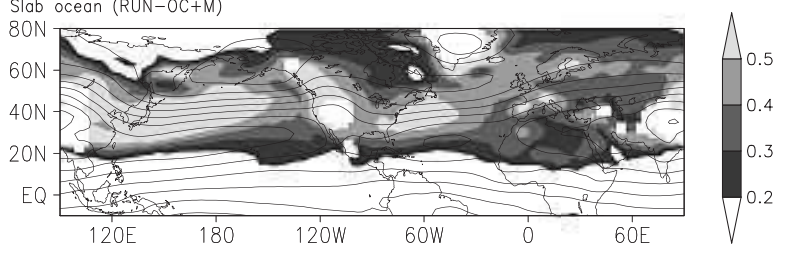

d) No mountains (RUN+OC-M)

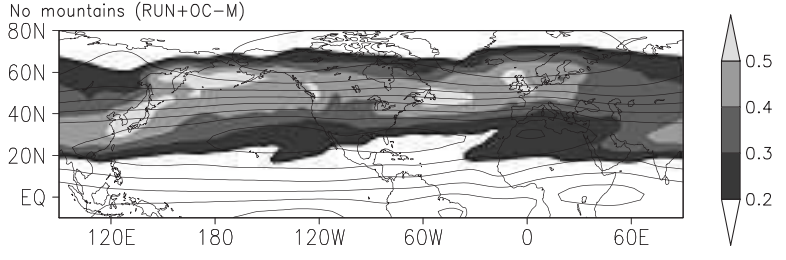

FIG. 3. The baroclinicity of he Northern Hemisphere wintermean storm tracks as revealed by the Eady growth rate $0.31(f / N)(\partial U / \partial z)\left(\right.$ day $\left.^{-1}\right)$ at $756 \mathrm{mB}$ for the four experiments with streamfunction overlaid (contour interval of $5 \times 10^{6} \mathrm{~m}^{2} \mathrm{~s}^{-1}$ ) and masking within $1 \mathrm{~km}$ of orography: (a) the control simulation, RUN $+\mathrm{OC}+\mathrm{M}$, with orography and a dynamic ocean; (b) RUN-OC-M, the ground state with a slab ocean and no orography; (c) RUN-OC $+\mathrm{M}$, with orography and a slab ocean; and (d) RUN + OC $-\mathrm{M}$, with a dynamic ocean and no orography.

similar notation for the other runs. The net effect of forcing by mountains and ocean dynamics on $X$ is given by $N=X_{+\mathrm{OC}+M}-X_{-\mathrm{OC}-M}=M+O+I$, where $M, O$, and $I$ represent the individual forcing from mountains, ocean dynamics, and the interaction between these two, and are diagnosed from the differences in the four experiments (Fig. 4, top). The transition from the ground state, whose only source of zonal asymmetry is the distribution of the continents, to the control state, which has much more asymmetry, is given by the net forcing $N=M+O+I$. Each term in this sum is formed from a difference, which may or may not be significantly different to zero, with respect to the $10 \mathrm{yr}$ of natural variability in each of the experiments. To avoid misleading interpretations, the relative importance of $M, O$, and $I$ are only displayed in the plots when the signal is $95 \%$ significantly different from zero. 

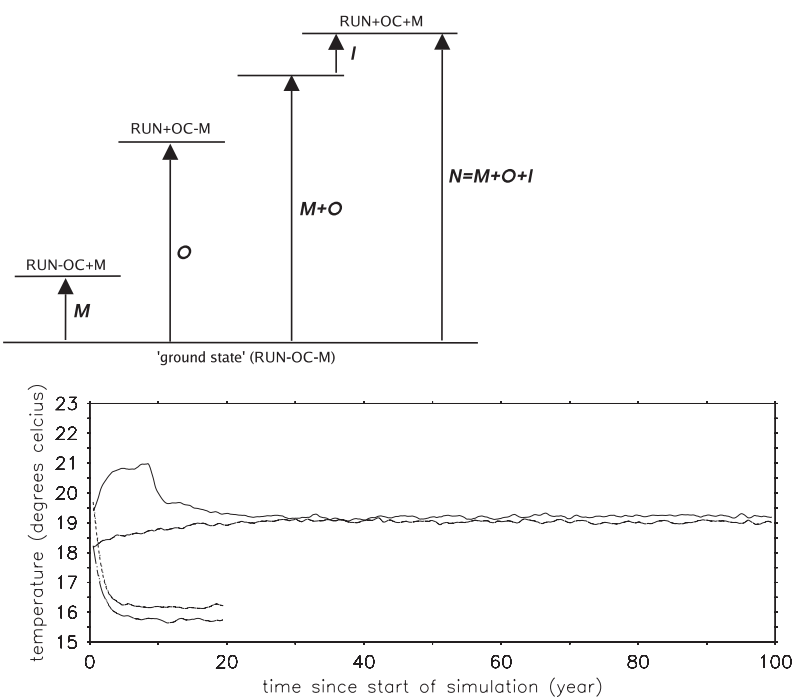

FIG. 4. (top) A schematic showing the differencing required to obtain the components of forcing from mountains $(M)$, ocean dynamics $(O)$, and the interaction between mountains and ocean dynamics $(I)$. For a chosen diagnostic, such as EKE, one obtains the forcing components through such differencing of that diagnostic in the relevant model runs. For example, to obtain the influence of mountains on $\operatorname{EKE}(M)$, one subtracts the EKE in the ground state (RUN-OC-M) from the EKE in $\mathrm{RUN}-\mathrm{OC}+\mathrm{M}$ Note that, due to the interaction (which may involve both linear and nonlinear processes) between mountains and ocean dynamics, the net forcing $(N)$ required to reach the control state $(\mathrm{RUN}+\mathrm{OC}+\mathrm{M})$ from the ground state $(\mathrm{RUN}-\mathrm{OC}-\mathrm{M})$ is not simply the sum $M+O$, but involves an extra contribution $(I)$. An example of such an interaction is the effect of mountains changing the pattern of ocean advection. (bottom) Monthly time series of global mean SST $\left({ }^{\circ} \mathrm{C}\right)$, with 12 -point boxcar smoothing. $\mathrm{RUN}+\mathrm{OC}+\mathrm{M}$ (solid), $\mathrm{RUN}+\mathrm{OC}-\mathrm{M}$ (dash), $\mathrm{RUN}-\mathrm{OC}+\mathrm{M}$ (short dash), and RUN-OC-M (long and short dash). The slab ocean runs equilibrate the fastest. In each case, the last $10 \mathrm{yr}$ of simulation are analyzed for this study.

While the separate forcings from orography and ocean dynamics are easy to understand, the nonlinear interaction is best understood as involving either (i) changes to ocean flow resulting from orography, such as stationary planetary waves forced by orography altering the underlying ocean, or (ii) changes to orographic processes resulting from ocean flow, such as the presence of ocean gyres affecting evaporation and subsequent relief rainfall.

\section{How is the storm-track pattern affected by orography and ocean dynamics?}

The effects of orography, ocean dynamics, and their interaction in the model experiments are now discussed in terms of diagnostic measures of the storm track, changes in the thermodynamic forcing by the ocean, and variations in the meridional heat transport.

\section{a. Diagnostics for the eddy variability in the storm tracks}

Storm-track signals of EKE and eddy temperature flux, as well as the mean flow pattern, are now considered in more detail.

\section{1) EDDY KINETIC ENERGY}

As discussed previously, the EKE in the control run is similar in form and magnitude to that diagnosed from 40-yr European Centre for Medium-Range Weather Forecasts (ECMWF) Re-Analysis (ERA-40; Figs. 5a, 1a), while the EKE in the ground state is more zonally uniform and slightly stronger (RUN-OC-M, Fig. 5b).

The net forcing, to produce the control state from the ground state, consists of a damping of slightly greater than $3 \mathrm{~m} \mathrm{~s}^{-1}$ over the midlatitudes between $20^{\circ}$ and $60^{\circ} \mathrm{N}$, excluding the central North Pacific, together with an intensification of up to $2 \mathrm{~m} \mathrm{~s}^{-1}$ near Iceland and north of Kazakhstan ( $N$, Fig. 5c). By preferentially damping the equatorward side of the storm track and intensifying the poleward side, this forcing shifts the storm track poleward, but not in a zonally uniform manner, and introduces along-track variability. There is also a net intensification of EKE in the tropics, but this does little to alter the large-scale storm-track pattern, which is strongest at the midlatitudes.

Orographic forcing acts mainly to damp storm-track EKE by up to $20 \%$ over land, downstream of orographic features such as the Tibetan Plateau, Rockies, and Alps ( $M$, Fig. 5d). Some of this damping extends into ocean regions between $10^{\circ}$ and $40^{\circ} \mathrm{N}$, while at the same time orographic forcing leads to an intensification of the storm track north of Kazakhstan. The strong orographic damping surrounding the Tibetan Plateau prevents the storm track from extending zonally across Eurasia, causing it to instead begin in the western Pacific and end upstream of Tibet. The orographic damping over North America can be considered to separate the single storm track into two Pacific and Atlantic parts.

Ocean forcing acts to damp the southern flank of the storm track in the ground state and intensify its northern flank, typically by up to $20 \%$, thus shifting the storm track poleward $(O$, Fig. $5 \mathrm{e})$. Some along-track variability in the ocean forcing and cancellation with mountain forcing gives the storm track its poleward tilt in the Atlantic. Ocean forcing is responsible for the net intensification of the EKE in the tropics.

The interaction term between orography and ocean forcing is limited to only localized regions of significance, intensifying the storm track over the Tibetan Plateau and in the eastern Pacific, and damping in the eastern Atlantic and at high latitudes (I, Fig. 5f). 
a) Control $(R \cup N+O C+M)$

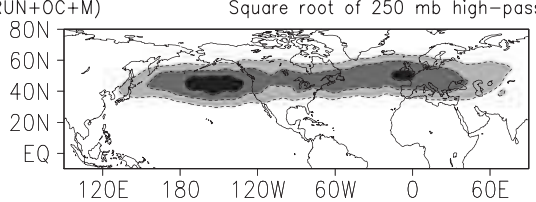

b) 'Ground state': slab ocean, no mountains (RUN-OC-M)

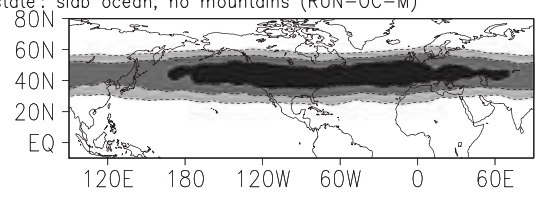

c) Net forcing: $\mathrm{N}=\mathrm{M}+\mathrm{O}+\mathrm{I}$

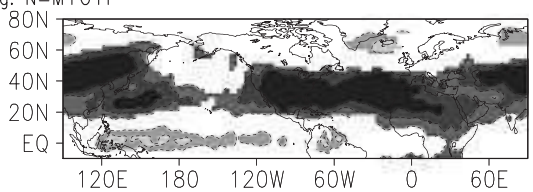

d) Orographic forcing: $M$

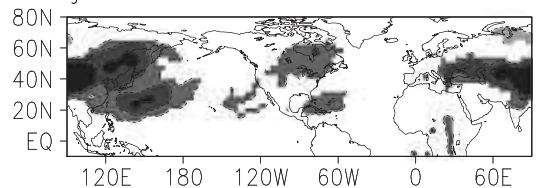

e) Ocean forcing: 0

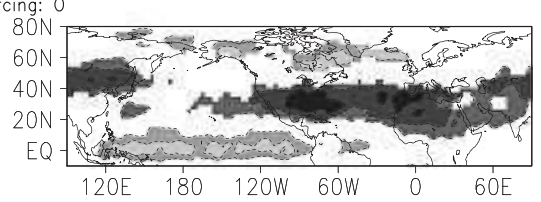

f) Interaction:

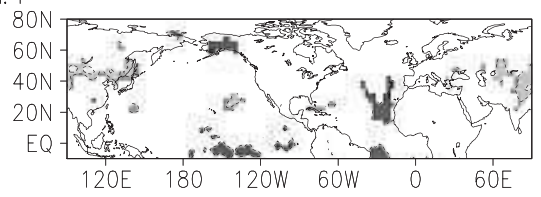

FIG. 5. Control, ground state, and individual forcing terms related to the square root of the mean 250-mb high-pass EKE (shaded, $\mathrm{m} \mathrm{s}^{-1}$ ). (a) The control run, $\mathrm{RUN}+\mathrm{OC}+\mathrm{M}$, (b) the ground state, RUN-OC-M, (c) the net forcing to go from the ground state to the control, $N=M+O+I$, (d) the orographic forcing $M$, (e) the forcing from ocean advection $O$, and (f) the forcing from the interaction between the orography and ocean advection $I$. Note that in (c)-(f), the contour intervals are nonuniform. Also, forcing effects that are less than $95 \%$ significantly different from zero are not shaded.

\section{2) EDDY TEMPERATURE FLUX}

The northward eddy temperature flux is a marker of baroclinic instability, because baroclinic instability is the main mechanism for atmospheric poleward heat transfer at mid- to high latitudes. In the ground state, there is only one EKE maximum (Fig. 5b), but two $\overline{v^{\prime} T^{\prime}}$ maxima at $756 \mathrm{mb}$ (Fig. 6b), as in the Eady growth rate (Fig. 3b). This more complicated pattern reflects the way in which baroclinic instability effectively switches off over continents and switches on again as ocean is encountered. The maximum in $\overline{v^{\prime} T^{\prime}}$ in the Pacific is up-

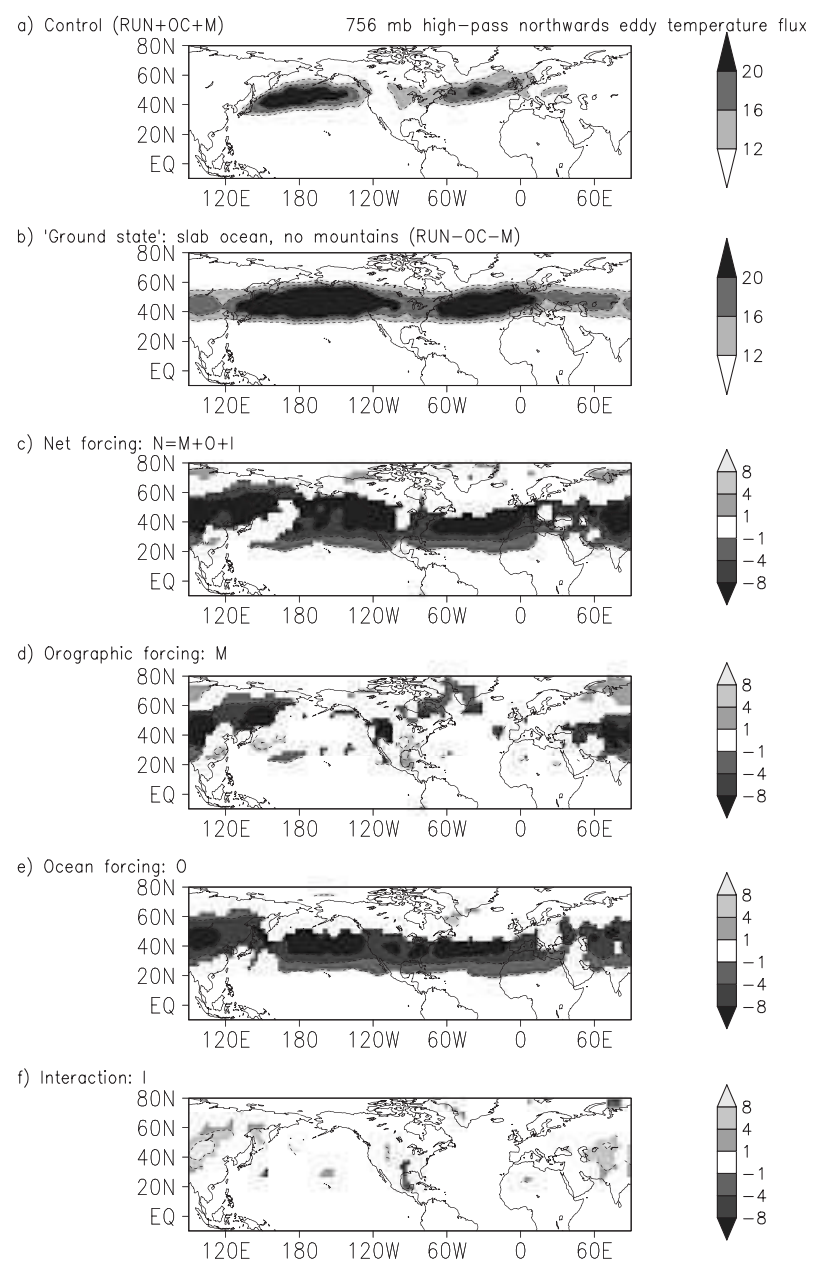

FIG. 6. As in Figs. 5a-f, but for the 756-mb high-pass $\overline{v^{\prime} T^{\prime}}$ (shaded, $\left.\mathrm{m} \mathrm{s}^{-1} \mathrm{~K}\right)$.

stream of the maximum in EKE, reflecting how eddies provide a poleward heat flux within the storm-track entrance and subsequently amplify downstream.

The net forcing ( $N$, Fig. $6 \mathrm{c}$ ) acts largely to damp $\overline{v^{\prime} T^{\prime}}$ over land and to damp the southern flank of the storm track over the ocean sectors, weakening the eddy temperature flux overall and shifting it poleward. There is minor intensification at high northern latitudes. Orography again tends to damp $\overline{v^{\prime} T^{\prime}}$ over land by up to $50 \%$, but with some intensification over northern Eurasia and in local regions downstream of the Tibetan Plateau and the Rockies ( $M$, Fig. 6d). Ocean forcing leads to a poleward shift of the poleward eddy temperature flux, damping by $50 \%$ on the equatorward side of the storm track, with some local intensification over Labrador $(O$, Fig. 6e). The interaction intensifies the poleward temperature flux over Tibet, but not strongly enough to counteract the opposing damping over land from $M$ and $O$ ( $I$, Fig. $6 \mathrm{f})$, which causes along-track variability. 
Hence, the poleward atmospheric eddy temperature flux is localized over the ocean because of the combined effect of orographic forcing and ocean dynamics, with ocean dynamics tending to shift the pattern poleward.

\section{3) MEAN FLOW PATTERN}

The storm-track eddies are advected by, draw energy from, and feed back momentum onto the mean jets as they undergo baroclinic life cycles. In this way, the eddies and the mean flow are intrinsically linked, and thus must be considered together to understand either part. The mean flow pattern at $250 \mathrm{mb}$ in the ground state is generally zonally symmetric, with along-track variability resulting from the continental distribution, with weaker flow as the jet diverges slightly over Europe (RUN-OC-M, Fig. 7b). In comparison, the midlatitude jet structure in the control state has a more realistic northeastward tilt over the oceans and a marked alongtrack variability in intensity (RUN+OC+M, Fig. 7a).

The net changes necessary for going from the ground state to the control are diagnosed using a vector summation for the flow prior to displaying the separate contributions in terms of speed and streamfunction pattern. The net forcing $(N)$ damps the eastward flow over midlatitudes from the central Pacific to western Europe, and also consists of a superposition of large-scale recirculations that represent stronger stationary waves $(N$, Fig. 7c). This pattern of the stationary waves compares reasonably well to that from National Centers for Environmental Prediction-National Center for Atmospheric Research (NCEP-NCAR), as shown in Held et al. (2002).

Orographic forcing causes a northeastward tilt of the jet over the Pacific and Atlantic through its strong meridional components and strong northeastward forcing near Japan and the Gulf of Mexico, associated with stationary waves from the Tibetan Plateau and the Rockies ( $M$, Fig. 7d). This wave train extends equatorward from Tibet.

Ocean dynamics acts mainly to damp the southern flank of the westerly jet in the ground state $(O$, Fig. $7 \mathrm{~b})$ in a zonal manner from $140^{\circ} \mathrm{E}$ to $0^{\circ}$ and to damp the northern flank over Eurasia. Ocean forcing causes the jet to shift poleward across a band extending from the western Pacific right across to the eastern Atlantic $\left(140^{\circ} \mathrm{E}-0^{\circ}\right)$, with accompanying northeastward tilt over Japan and a southeastward tilt over Europe. There is also a slight equatorward shift of the jet over Eurasia.

The forcing from the interaction between ocean dynamics and orographic forcing has a significant meridional component (I, Fig. 7f), which causes a slight southeastward tilt over the central Pacific and makes a contribution to the northeastward tilt over the North Atlantic.

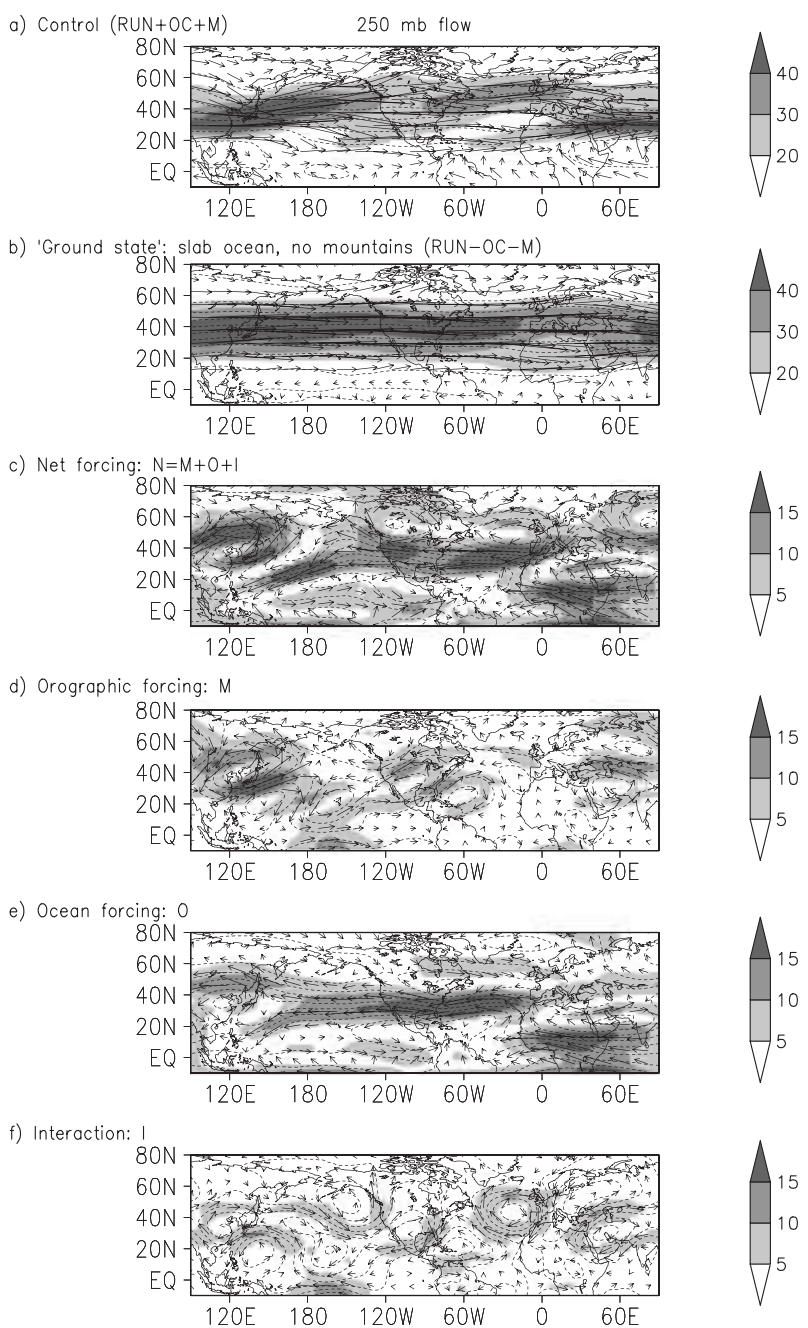

FIG. 7. As in Figs. 5a-f, but for the 250-mb mean velocity (vectors), streamfunction (dashed), and speed (shaded, $\mathrm{m} \mathrm{s}^{-1}$ ).

\section{4) E-VECTORS AND THE EDDY-MEDiATED RESPONSE}

Transient eddies within the storm track can interact with and affect the large-scale mean flow pattern and stability. Eddies transport momentum from source to sink, and $\mathbf{E}$-vectors (Hoskins et al. 1983) provide more information about typical eddy life cycles and reveal the eddy-mediated response to anomalous forcing. The control state (RUN $+\mathrm{OC}+\mathrm{M}$, Fig. 8a) has eastward 250-mb high-pass E-vectors in the storm track, which diverge over the entrances of the Pacific and Atlantic storm track and converge over the exits and southern flank. The $\mathbf{E}$-vector $\mathbf{E}=\left(\overline{v^{\prime 2}-u^{\prime 2}},-\overline{u^{\prime} v^{\prime}}\right)$ describes changes to eddy isotropy. For example, in the extratropics transient eddies tend to be meridionally elongated, hence the tendency for an eastward $\mathbf{E}$-vector and group propagation relative to the mean flow. Strictly, 

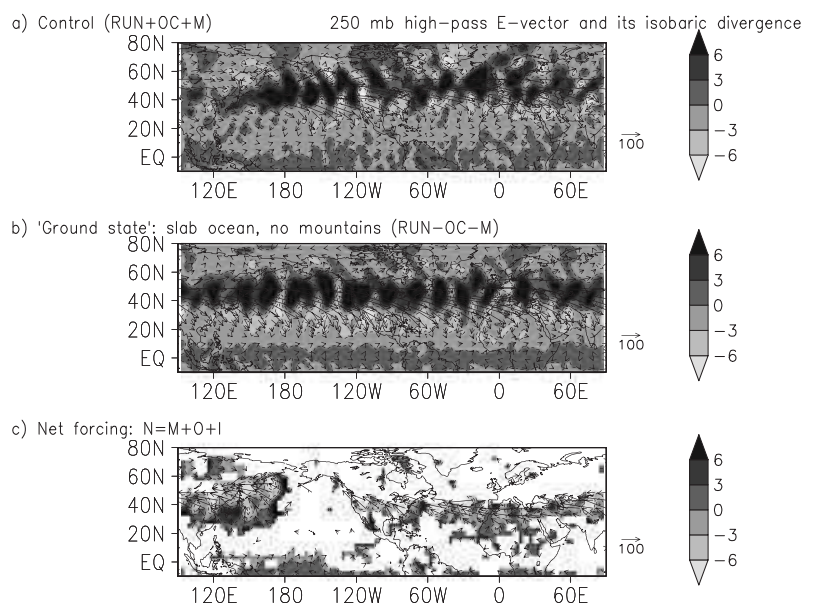

d) Orographic forcing: $M$

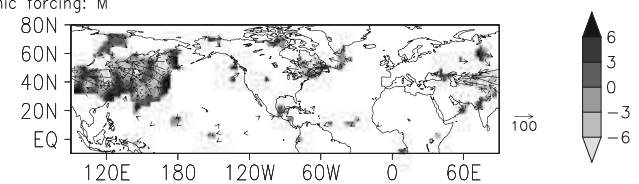

e) Ocean forcing: 0

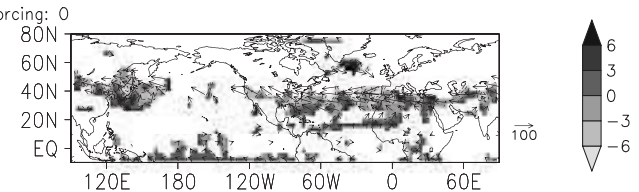

f) Interaction: I

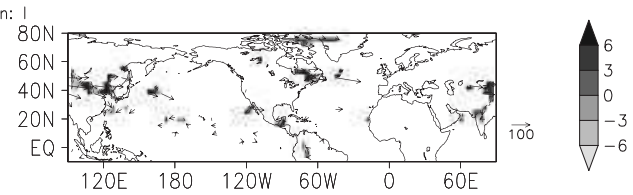

FIG. 8. As in Figs. 5a-f, but for the 250-mb E-vector (vectors, $\mathrm{m}^{2} \mathrm{~s}^{-2}$ ) and its isobaric divergence (shaded, $10^{-5} \mathrm{~m} \mathrm{~s}^{-2}$ ). The Evectors are analogous to a flux of westward momentum, and their divergence is equivalent (to within a gauge) to an eastward acceleration of the mean flow by the eddies. See the text for more details.

the $\mathbf{E}$-vector is equivalent to a flux of westward momentum, and regions of divergence are associated with an eastward acceleration of the mean flow by the eddies. Therefore, in both the control state $(\mathrm{RUN}+\mathrm{OC}+\mathrm{M}$, Fig. 8a) and the ground state (RUN-OC-M, Fig. 8b), transient eddies generally accelerate the mean flow eastward within the storm track. In the ground state, there is more zonal symmetry than in the control, with eddy-mean interaction being strongest over the ocean in the latter. In both the control and ground state, eddies provide a weak westward acceleration to the mean flow at around $20^{\circ} \mathrm{N}$ and a weak eastward acceleration near the equator. The net forcing (Fig. 8c) acts to provide a generally westward E-vector over eastern Eurasia and the western Pacific and over the southern flank of the midlatitude storm track at $40^{\circ} \mathrm{N}$ from the eastern Pacific extending eastward across the Atlantic and Eurasia.
This net forcing is accompanied by an anomalous convergence of the $\mathbf{E}$-vector field, reducing the overall eastward acceleration provided by the eddies on the mean flow, and thus weakening the midlatitude jet over eastern Eurasia and from the eastern Pacific eastward across the Atlantic and Eurasia.

In the tropical Pacific, the net forcing shows a weak E-vector divergence, equivalent to a weak eastward acceleration of the mean flow by the eddies. Examination of the forcing components (Figs. 8d-f) shows that this tropical source of eddy forcing (and eddy-mean forcing) is due to ocean dynamics. Ocean dynamics also account for much of the net deceleration of the midlatitude jet and strengthening of the planetary stationary wave pattern over the Atlantic through tilt to the mean flow. Orographic forcing predominantly affects the $\mathbf{E}$-vector field over and downstream of the Tibetan Plateau, reinforcing the effect of ocean dynamics and providing a damping of the eastward jet there. For example, one can see that the anomalous E-vectors are oriented northwestward over the western Pacific (Fig. 8d). Because $-\mathbf{E}$ represents a flux of eastward momentum and the divergence of an eastward acceleration $\mathbf{E}$, the effect of the Tibetan Plateau is to force the almost zonal ground-state mean flow (Fig. 7b) and eddies (Fig. 8b) to alter their individual momentum by, respectively, tilting northeastward and fluxing eastward momentum southeastward. This is achieved by the eddy deceleration of the northern flank of the ground-state jet over eastern Eurasia. The associated changes in eddy isotropy lead to the altered eddy eastward momentum flux, and ignoring dissipative forcing, act to balance the overall eastward momentum budget. In this way, the generation and propagation of transient eddies provides a mechanism for communicating the forcing from orography, seen as a planetary wave train. The interaction between ocean dynamics and orography, however, has little effect on $\mathbf{E}$-vectors (Fig. 8f).

Although we can now state that ocean dynamics decelerate the midlatitude eastward jet and increase its tilt through an eddy-mediated process, we must now consider surface boundary forcing for the likely source of these changes. It is here that ocean dynamics are able to begin to alter the transient eddy field and therefore eventually the large-scale mean flow.

\section{b. Thermodynamic forcing from the ocean}

The land-sea contrasts and ocean transport of heat are clearly playing a role in affecting the atmospheric structure. Now examine how the sea surface temperature and surface heat flux is altered within the model experiments, because the shear flow stability of the atmosphere is strongly dependent on the surface temperature distribution (Hoskins et al. 1985). 


\section{1) $\operatorname{SST}$}

The coupled model integrations for the control are for $100 \mathrm{yr}$ with the ocean initialized from the World Ocean Atlas (WOA) climatology (Levitus et al. 1998), and integrations for the ground state are for $20 \mathrm{yr}$ with the slab ocean being initialized from zonal mean of the climatology. In the ground state, the SST pattern remains nearly zonal with SST gradients being slightly weaker on the eastern side of each basin (RUN$-\mathrm{OC}-\mathrm{M}$, Fig. 9b). In the control, the winter-mean SST pattern is more realistic, with a stronger tilt of the isotherms in the Atlantic (RUN+OC+M, Fig. 9a). The SST in the control is much warmer than in the ground state at midlatitudes, by $3^{\circ}-6^{\circ} \mathrm{C}$ in the Pacific and by $6^{\circ} \mathrm{C}$ in the Atlantic ( $N$, Fig. 9c). The control is up to $6^{\circ} \mathrm{C}$ cooler than the ground state in the equatorial Pacific, and slightly less so in the equatorial Atlantic $(N$, Fig. 9c).

Ocean dynamics, not surprisingly, is the most important process leading to the midlatitude warming, which is most enhanced on the western side of the basin $(O$, Fig. 9e). Ocean forcing is also responsible for equatorial cooling, through upwelling of cold water and horizontal advection of warm water poleward. This equatorial cooling is seen in the model SST bias (Fig. 1e), but is common in coarse-resolution OGCMs.

In contrast, orographic forcing provides a slight warming of $1^{\circ}-3^{\circ} \mathrm{C}$ over the central Atlantic and forces an SST dipole of $6^{\circ} \mathrm{C}$ amplitude in the western Pacific $(M$, Fig. 9d). The interaction term partly opposes this orographic forcing ( $I$, Fig. 9f) and reduces SST over the Pacific and intensifies SST over the northern Atlantic, near Iceland, by over $6^{\circ} \mathrm{C}$. This nonlinear interaction is of a similar magnitude to that of $O$ and $M$, thus illustrating the complicated interplay of forcing from orography and ocean dynamics.

\section{2) SST GRADIENT}

To illustrate these changes in SST more clearly, now consider the meridional gradient in SST. In the ground state, the SST gradient is strongest and most negative across both basins at around $40^{\circ} \mathrm{N}$ (Fig. 10b), coincident with the latitude of the storm track. In the control, the SST gradient becomes most negative over the western side of each basin and in the northern North Atlantic (Fig. 10a). Again, this change in SST gradient reflects changes in the overlying storm track. The overall change in SST gradient between the ground state and the control primarily involves a poleward shift in the SST gradient, which is weakened in magnitude between $20^{\circ}$ and $40^{\circ} \mathrm{N}$ and strengthened north of $50^{\circ} \mathrm{N}$ $(N$, Fig. 10c).

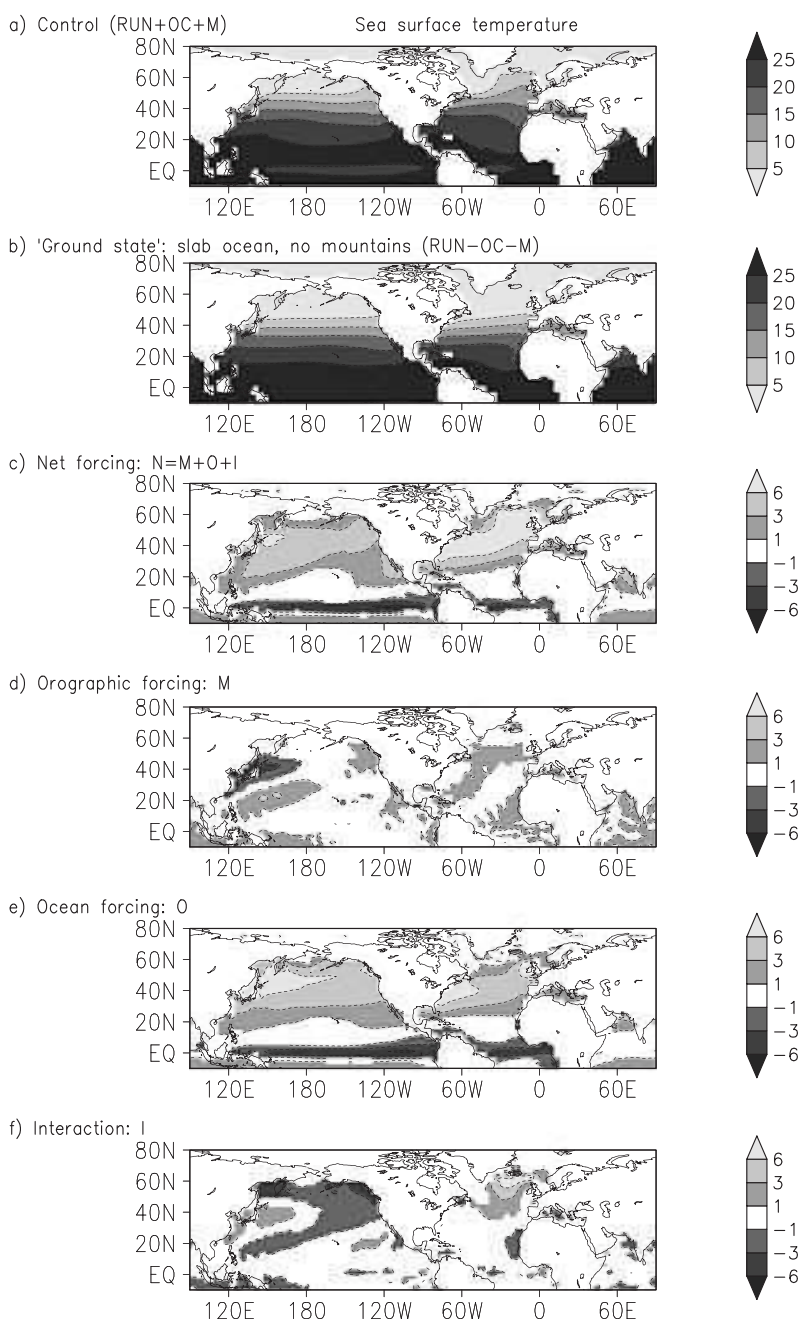

FIG. 9. As in Figs. 5a-f, but for the sea surface temperature (shaded, ${ }^{\circ} \mathrm{C}$ ).

This shift in SST gradient is primarily due to ocean dynamics where the wind-driven gyre circulation leads to a tightening of SST gradients at the intergyre boundaries and a general warming of the midlatitudes $(O$, Fig. 10e). However, the action of orography and nonlinear interaction complicate this response, with the nonlinear interaction further enhancing the SST gradient in the northern North Atlantic, while there is a complicated partial cancellation of the effects from $M, O$, and $I$ in the midlatitude North Pacific (Figs. 10c-f).

In the tropical Pacific, ocean dynamics leads to weakening of the background meridional SST gradient. This reflects the extensive cold tongue and in a sense would imply a weakening of the overlying baroclinicity $(N$, Fig. 10c). However, we do not see strong evidence of this signal in the local 756-mb Eady growth rate (Fig. 3).

In terms of the effect of the midlatitude SST gradient on the overlying atmosphere, heuristically, a sharper 
a) Control (RUN+OC+M) d/dy (Sea surface temperature)

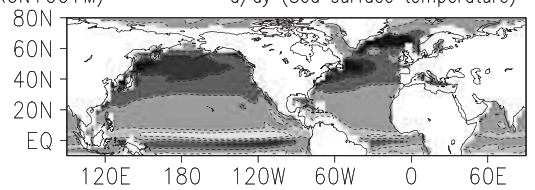

b) 'Ground state': slab ocean, no mountains (RUN-OC-M)

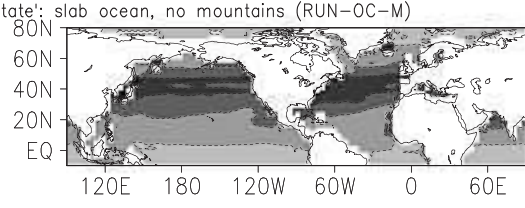

c) Net forcing: $\mathrm{N}=\mathrm{M}+\mathrm{O}+\mathrm{I}$

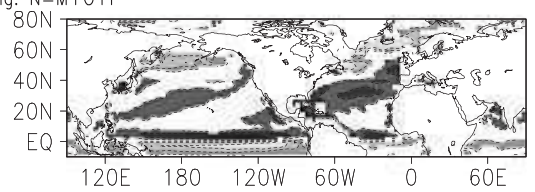

d) Orographic forcing: $M$

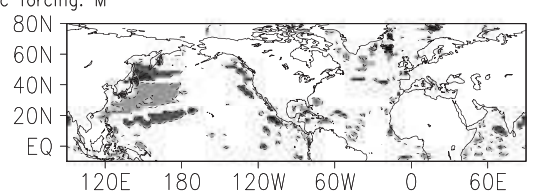

e) Ocean forcing: 0

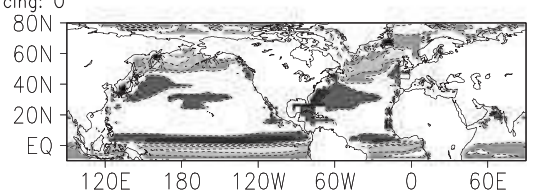

f) Interaction:

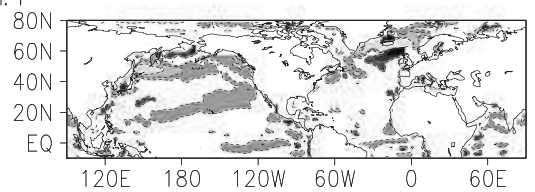

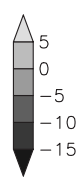
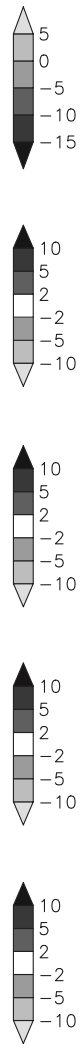

FIG. 10. Same as in Figs. 5a-f, but for the meridional gradient of sea surface temperature $\left(10^{-6} \mathrm{~K} \mathrm{~m}^{-1}\right)$.

meridional gradient of potential temperature over the Rossby deformation length scale is expected to lead to increased available potential energy for baroclinic instability and, thus, stronger storm tracks. Indeed, ocean dynamics lead to a poleward shift in SST gradient, which is associated with a poleward shift in the baroclinicity of the lower atmosphere as measured by the Eady growth rate.

\section{3) Surface HeAt FluX}

Given the subtle connection between SST and the overlying baroclinicity, consider how the surface heat flux between the atmosphere and ocean is modified.

In the ground state, the pattern of net surface heat loss (lost from the ocean to the atmosphere) is broadly zonal with a maximum loss between $40^{\circ}$ and $50^{\circ} \mathrm{N}$ across both basins (RUN-OC-M, Fig. 10b). In contrast, in the control state, the maximum surface heat loss reaching $300 \mathrm{~W} \mathrm{~m}^{-2}$ shifts toward the western side of the Pacific basin and northward toward the northern North Atlantic (RUN+OC+M, Fig. 10a). While the heat loss of the control is more plausible than in the ground state, the surface heat loss does not capture the localized maxima over the Gulf Stream and Kuroshio Extension, since the ocean resolution is too coarse; see climatologies such as that of Grist and Josey (2003). The net forcing between these two states includes an increased surface heat loss of between 60 and $180 \mathrm{~W} \mathrm{~m}^{-2}$ over the Kuroshio and Gulf Stream, north of $55^{\circ} \mathrm{N}$ in the Pacific and more than $180 \mathrm{~W} \mathrm{~m}^{-2}$ in the northern Atlantic ( $N$, Fig. 11c). Conversely, there is an increase in the heat flux into the ocean, in the tropical Pacific, and in the eastern side of the subtropical Atlantic. There is an ocean uptake of $60 \mathrm{~W} \mathrm{~m}^{-2}$ in the tropical Pacific resulting from the net forcing related to the extended SST cold tongue ( $N$, Fig. $11 \mathrm{c})$.

This increase in surface heat loss is again primarily controlled by the inclusion of ocean dynamics where the gyre circulation leading to the surface heat loss over the boundary currents and the overturning circulation leading to the loss over the northern Atlantic $(O$, Fig. 11e). Conversely, the ocean dynamics leads to a surface heat flux gain in the equatorial Pacific, with this being connected to the advective setup of the Pacific cold tongue. In comparison, orography and the interaction increase the surface heat loss near Iceland ( $M$ and $I$, Figs. 11d,f), while orography leads to a quadrupole pattern over the western Pacific, associated with stationary waves generated from Tibet (Fig. 7d).

\section{4) RESPONSE TO CHANGES IN THE TROPICS}

The changes to the surface boundary conditions in the tropics are mainly due to the effect of ocean dynamics (Figs. 9e, 10e, and 11e), which reduces SST, reverses the background meridional SST gradient, and increases net surface ocean heat uptake near the equator. Given this forcing by the ocean, there can be both local (tropical) and nonlocal (extratropical) responses to these changes.

Locally, the ocean forcing leads to the tropical Pacific developing a weak mean flow recirculation, enhancement of the moisture content (not shown) and the local EKE (Fig. 5e), and a weak eastward acceleration of the mean flow implied by $\mathbf{E}$-vector divergence (Fig. 8e). Therefore, we assume that these changes to EKE are probably related to the effect of moist convective processes or advection from the extratropics (e.g., Emanuel 1989), rather than to local baroclinic instability.

Whether the tropical changes are leading to an extratropical response, such as the weakening in eastward acceleration at midlatitudes (Fig. 8e), is more 

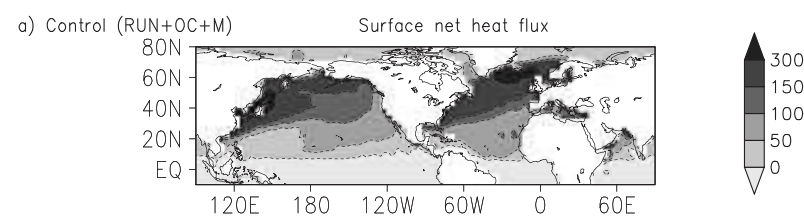

b) 'Ground state': slab ocean, no mountains (RUN-OC-M)
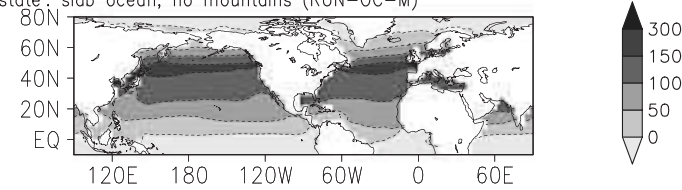

c) Net forcing: $\mathrm{N}=\mathrm{M}+\mathrm{O}+\mathrm{I}$

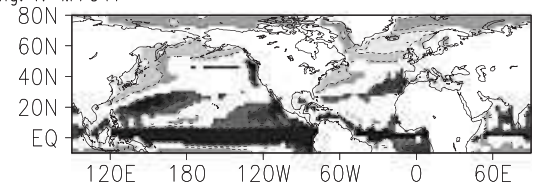

d) Orographic forcing: $M$

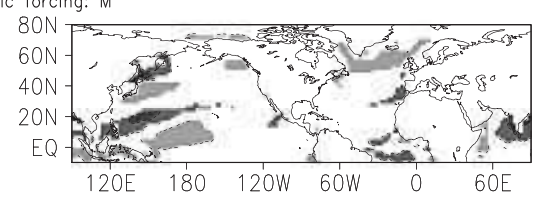

e) Ocean forcing: 0

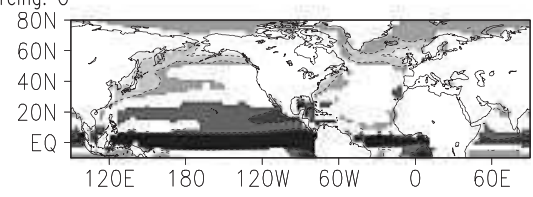

f) Interaction:
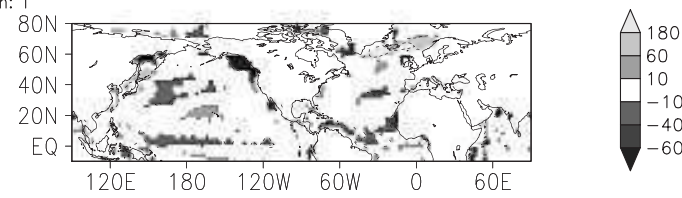

FIG. 11. Same as in Figs. 5a-f, but for the surface heat flux from ocean to atmosphere $\left(\mathrm{W} \mathrm{m}^{-2}\right)$.

difficult to discern, particularly as there is forcing from a combination of ocean dynamics $(O)$, orographic forcing $(M)$, and the nonlinear interaction $(I)$. These are among the concerns discussed in Held et al. (2002). While clear connections are difficult to identify, there are plausible mechanisms for an extratropical response to changes in the tropics. For example, Held et al. (1989) consider the extratropical response to $\mathrm{El} \mathrm{Niño} / \mathrm{La}$ Niña conditions and the creation of the Pacific-North American (PNA) pattern. They find that anomalous tropical heating has little extratropical influence on its own, and that transient eddies are needed for the teleconnection to midlatitudes. One may consider the role of ocean dynamics in our study as being analogous to the forcing provided by La Niña in Held et al. (1989), since both produce anomalous cooling in the equatorial Pacific. Held et al. (1989) also use $\mathbf{E}$-vectors to examine the teleconnection between tropics and extratropics (their Fig. 10), and they find that during La Niña conditions, eddies penetrate deeper into the tropics than in El Niño conditions, and that they also force the jet poleward and cause blocking in the central Pacific, therefore weakening the storm-track activity. This eddy-mediated teleconnection is crucial for the production of the PNA pattern in the stationary mean flow. In our study we see that ocean dynamics also allow eddy activity to penetrate deeper into the tropics (Fig. 8e), but their role in extratropical teleconnections is unclear in our study. In addition, Orlanski (2005) considers the response to anomalies in mid-Pacific baroclinicity and finds that a warming in the tropical Pacific is associated with an equatorward shift of the storm track (opposite for La Niña), which is linked to tropical baroclinicity changes, as well as by advection of eddy activity to the extratropics by the upper-level mean flow. In our study, we find that including ocean dynamics leads to a poleward shift in the midlatitude storm track, which is broadly consistent with the Orlanski (2005) mechanism, since we see a slight equatorial cooling and a weakening of eastern tropical Pacific baroclinicity. However, further support regarding the details of this mechanism, involving upstream seeding and downstream development, is beyond the scope of this study.

\section{c. Northward heat transport by the atmosphere and ocean}

To complement our picture of how the surface thermodynamic processes alter, now consider the 10 -yr timemean, zonally integrated atmosphere and ocean northward heat transport (NHT).

In the ground state, the total (atmosphere plus ocean) NHT reaches up to $5 \mathrm{PW}$ at $35^{\circ} \mathrm{N}$ and, by definition, is solely due to the atmosphere because the slab ocean is static (Figs. 12a,c, dashed line). In the control state, the total NHT is enhanced at all latitudes, with a maximum value of $6 \mathrm{PW}$ at $25^{\circ} \mathrm{N}$ (Fig. 12a, full line). This increase in heat transport is achieved by the ocean providing a heat transport reaching up to $2 \mathrm{PW}$ in the tropics (Fig. 12e, full line), as well as a slight poleward shift in the maximum atmospheric heat transport (Fig. 12c). Thus, the total NHT is primarily provided by the atmosphere, with the ocean providing a comparable contribution in the tropics (e.g., Held 2001; Czaja and Marshall 2006).

This increase in northward total heat transport occurs in both model experiments, including a dynamic ocean, the control case (Fig. 12a, full line), and the no-mountains case, identifying the dominant effect of the ocean forcing (Fig. 12b). Hence, in these experiments, we do not see the effect of the ocean transport being compensated by an opposing change in the atmospheric transport, as might be expected if a straightforward Bjerknes compensation 
a) Total NHT

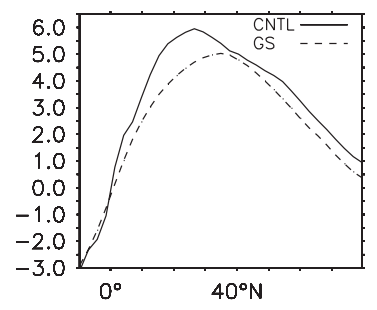

c) Atmosphere NHT

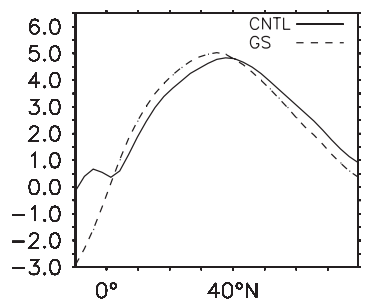

e) Ocean NHT
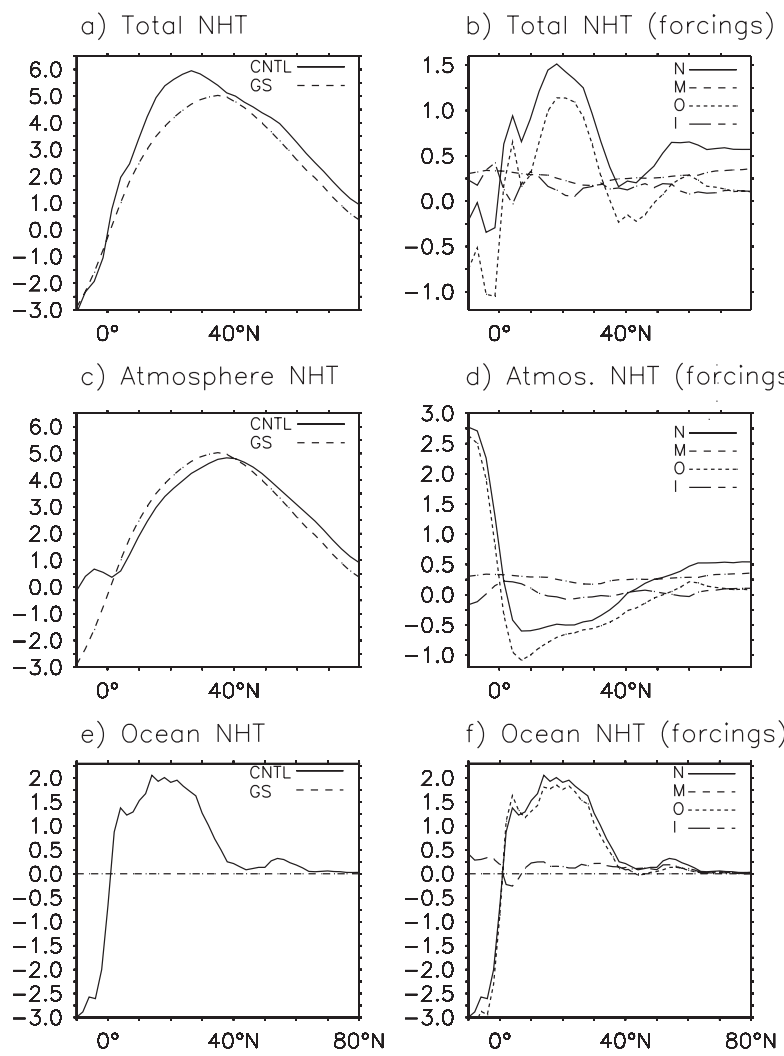

d) Atmos. NHT (forcings)

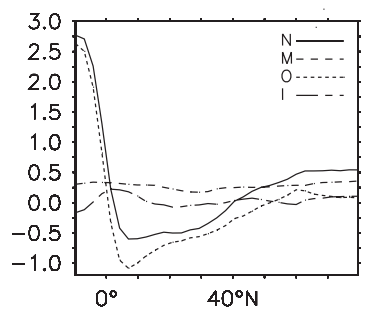

f) Ocean NHT (forcings)

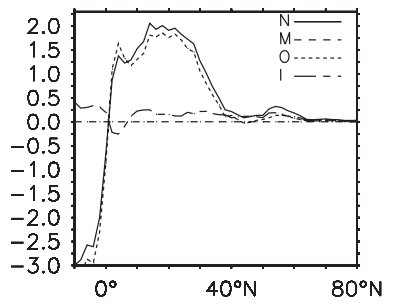

FIG. 12. Zonally integrated northward heat transport $(\mathrm{PW}=$ $10^{15} \mathrm{~W}$ ) and forcings, respectively, for the (a),(b) total, (c),(d) atmosphere, and (e),(f) ocean, shown for the 10-yr time mean. (e) The ground state (GS) and control (CNTL) scenarios are shown, with the northward ocean heat transport in the ground state being zero, because of a static slab ocean. (f) Note that the addition of mountains $(M)$ has no direct effect on the ocean northward heat transport, but does have influence through the interaction with ocean dynamics $(I)$.

was occurring (Bjerknes 1964). Instead, the inclusion of the ocean is altering the background climate state.

The atmospheric response to the inclusion of ocean dynamics is to carry less heat poleward at low latitudes, but then to carry more heat poleward at mid- to high latitudes (Fig. 12c). Thus, the additional heat carried poleward by the ocean at low latitudes is transferred by air-sea exchange to the overlying atmosphere at midlatitudes, and then increases the atmospheric heat transport. The area-integrated atmospheric NHT is nearly identical for the ground state and the control, partly reflecting the lack of any significant heat storage in the atmosphere.

In terms of the forcings of the total NHT, ocean dynamics increase the transport in the tropics between $10^{\circ}$ and $35^{\circ} \mathrm{N}$, as well as providing a slight weakening around $40^{\circ} \mathrm{N}$ and a strengthening around $60^{\circ} \mathrm{N}$ (Fig. 12b, dashed line). Introduction of orographic forcing and the interaction term generally have a weak influence in the zonal integral of up to $0.3 \mathrm{PW}$, and do not vary meridionally (Figs. 12b,d). However, the interaction term provides damping of NHT in the North Pacific and enhancement in the North Atlantic of up to 0.3-PW magnitude, which cancels in the zonal integral (not shown).

Ocean dynamics lead to an ocean NHT of up to 1.8 PW at $20^{\circ} \mathrm{N}$, and the interaction with orography provides an additional 0.2 PW (Fig. 12f). This low-latitude change due to ocean dynamics alters the SST distribution because more heat is transported from the equator. However, at midlatitudes around $40^{\circ} \mathrm{N}$, ocean heat transport becomes small (Fig. 12e) and the atmosphere takes up this heat carried by the ocean and transports the heat poleward in both the mean flow and in the time-varying flow associated with the storm track. The atmospheric NHT at the storm-track latitudes is shifted poleward due to forcing from ocean dynamics (Fig. 12d), illustrating that the ocean still has an effect in the total NHT despite the ocean NHT being diminished at these latitudes.

\section{Summary and discussion}

A coupled climate model is used to examine the individual effects of ocean dynamics, orography, and their nonlinear interaction on the storm tracks in the Northern Hemisphere winter. Their separate effects are diagnosed from the differences between model experiments with or without mountains and with a realistic ocean or a slab ocean.

In the model experiment without orography and ocean dynamics, there is still a storm track, albeit more intense and broader than that observed in reality. Hence, in these experiments, the maintenance of the storm track does not need to involve either orographic forcing or a supply of heat by ocean western boundary currents, and other fundamental processes are at work. The formation of strong zonal jets and storm tracks may be simply understood as poleward-moving upper air in the tropics being zonally deflected by $30^{\circ} \mathrm{N}$ through largescale angular momentum conservation, and then how the strength of these jets is enhanced over the warm, moist ocean and weakened over the land. A more realistic storm track is obtained as orography and ocean dynamics are included: the storm track becomes sharper, shifts poleward, and has more along-track variability.

Ocean dynamics transport heat poleward and form characteristic gyre and overturning circulations. Like most OGCM studies, we do not consider the long timescale variability of the overturning circulation because 
of the computational expense, but instead we consider the response to the rapidly equilibrating upper ocean. Because of the ocean dynamics, the broad maxima in surface net heat loss and meridional gradient of SST present in the ground state become concentrated within the western boundary current extensions of the Kuroshio and Gulf Stream. These regions of enhanced SST gradient are also displaced poleward, matching the poleward shift in atmospheric baroclinicity.

Ocean transport of heat in the tropics leads to a poleward shift in the maximum atmospheric northward heat transport: the atmospheric heat transport reduces in the tropics and increases in the mid and high latitudes. Accompanying this poleward shift in the maximum atmospheric heat transport is a concomitant shift in the midlatitude storm tracks, which is to be expected because the synoptic-scale eddies are the dominant process fluxing heat poleward at midlatitudes. The effect of the ocean dynamics on the storm track is most pronounced over the Atlantic basin where the ocean poleward heat transport is largest.

Orography induces along-track variability and dampens the storm track over and downstream of the major mountain ranges of the Tibetan Plateau, Rockies, and Alps. The orographic forcing is dominated by the effect of the Tibetan Plateau, generating a stationary planetary wave train with alternating pressure anomalies, inducing a northeastward tilt over the Pacific storm-track entrance. The interaction between the ocean dynamics and orography often partially cancels the other forcings and is important only over localized regions, such as enhancing the contrast between the Atlantic and Pacific.

The large-scale adjustment to forcing from ocean dynamics and orography is shown to have a significant eddy-mediated component, as seen in the $\mathbf{E}$-vector diagnostics. At midlatitudes, ocean and orographic forcing acts, via the transient eddy field, to weaken the eastward eddy-mean acceleration on the jet, and to insert zonal asymmetry and tilt to the flow. This eddy forcing causes the jet and storm track to tilt over the Pacific and Atlantic, and to shift poleward. In effect, eddies help to spread the influence of orographic forcing through changes associated with the generation of a stationary planetary wave train from the Tibetan Plateau.

Our study is also relevant to the question of how surface temperature contrasts across the North Atlantic are determined. Seager et al. (2002) argued that the west-east contrasts in air temperature across the North Atlantic are not determined by ocean heat transport across the basin, but are instead determined by the orographically forced atmospheric standing wave pattern. In our study, ocean dynamics is found to play a more subtle role, tightening the SST gradients on the
TABLE A1. Mixing parameters of the ocean component of the FORTE model.

\begin{tabular}{ll}
\hline \hline Lateral eddy viscosity & $5 \times 10^{3} \mathrm{~m}^{2} \mathrm{~s}^{-1}$ \\
Lateral eddy diffusivity & $0 \mathrm{~m}^{2} \mathrm{~s}^{-1}$ \\
Bottom drag coefficient & $0.001 \mathrm{~s}^{-1}$ \\
Vertical viscosity & $10^{-3} \mathrm{~m}^{2} \mathrm{~s}^{-1}$ \\
Vertical diffusivity & $5 \times 10^{-5} \mathrm{~m}^{2} \mathrm{~s}^{-1}$ \\
Isopycnal tracer diffusivity & $5 \times 10^{3} \mathrm{~m}^{2} \mathrm{~s}^{-1}$ \\
Steep slope horizontal diffusivity & $5 \times 10^{3} \mathrm{~m}^{2} \mathrm{~s}^{-1}$ \\
Isopycnal thickness diffusivity & $5 \times 10^{3} \mathrm{~m}^{2} \mathrm{~s}^{-1}$ \\
Max slope of isopycnals & 0.002
\end{tabular}

western side of ocean basins and increasing the northward heat transport. This change in the surface thermal boundary layer is associated with changes in the overlying baroclinicity of the atmosphere, leading to a poleward shift in the mean flow and associated position of the storm track. This connection between ocean dynamics and the overlying storm tracks might be further enhanced in coupled models with higher ocean resolution, which include the extension of the warm western boundary currents into the basin interior.

Acknowledgments. This study was cofunded by the U.K. Natural Environment Research Council COAPEC project (NER/T/S/2000/00305) and Oceans2025 Theme 1: Climate, Ocean Circulation and Sea Level. We are grateful to ECMWF for supplying ERA-40 data; and we thank Matthew Brand for suggesting the experimental formalism and for technical support; Robin Smith for support in the early stages of the project; Mike Blackburn for vital help with IGFLUX; and Chris Hughes, Tim Woollings, and two anonymous reviewers for useful discussions.

\section{APPENDIX}

\section{Ocean Component of FORTE}

The equations and numerical discretization of the ocean component of the FORTE model are well documented by Webb (1996). The version used here has been improved by incorporation of the Gent-McWilliams eddy parameterization and isopycnic mixing using the skew-flux formulation of Griffies (1998). We present the ocean model mixing parameters in Table A1. The simple thermodynamic sea ice model is described in detail by Forster et al. (2000). The only change made for implementation in FORTE was to include a relaxation of the sea surface temperature to the freezing point of water in grid boxes containing ice, with a relaxation time scale of 30 days. 


\section{REFERENCES}

Baldwin, M. P., P. B. Rhines, H.-P. Huang, and M. E. McIntyre, 2007: The jet-stream conundrum. Science, 315, 467-468.

Bjerknes, J., 1964: Atlantic air-sea interaction. Advances in Geophysics, Vol. 10, Academic Press, 1-82.

Black, R. X., and R. M. Dole, 2000: Storm tracks and barotropic deformation in climate models. J. Climate, 13, 2712-2728.

Blackmon, M. L., J. M. Wallace, N.-G. Lau, and S. L. Mullen, 1977: An observational study of the Northern Hemisphere wintertime circulation. J. Atmos. Sci., 34, 1040-1053.

Blaker, A. T., B. Sinha, V. O. Ivchenko, N. C. Wells, and V. B. Zalesny, 2006: Identifying the roles of the ocean and atmosphere in creating a rapid equatorial response to a Southern Ocean anomaly. Geophys. Res. Lett., 33, L06720, doi:10.1029/2005GL025474.

Chang, E. K. M., S. Lee, and K. L. Swanson, 2002: Storm track dynamics. J. Climate, 15, 2163-2183.

Czaja, A., and J. Marshall, 2006: The partitioning of poleward heat transport between the atmosphere and ocean. J. Atmos. Sci., 63, 1498-1511.

Emanuel, K. A., 1989: The finite-amplitude nature of tropical cyclogenesis. J. Atmos. Sci., 46, 3431-3456.

Forster, P., M. Blackburn, R. Glover, and K. P. Shine, 2000: An examination of climate sensitivity for idealised climate change experiments in an intermediate general circulation model. Climate Dyn., 16, 833-849.

Griffies, S. M., 1998: The Gent-McWilliams skew flux. J. Phys. Oceanogr., 28, 831-841.

Grist, J. P., and S. A. Josey, 2003: Inverse analysis adjustment of the SOC air-sea flux climatology using ocean heat transport constraints. J. Climate, 16, 3274-3295.

Held, I. M., 2001: The partitioning of the poleward energy transport between the tropical ocean and atmosphere. J. Atmos. Sci., 58, 943-948.

— S. W. Lyons, and S. Nigam, 1989: Transients and the extratropical response to El Niño. J. Atmos. Sci., 46, 163-174.

—, M. Ting, and H. Wang, 2002: Northern winter stationary waves: Theory and modeling. J. Climate, 15, 2125-2144.

Hoskins, B. J., and P. J. Valdes, 1990: On the existence of storm tracks. J. Atmos. Sci., 47, 1854-1864.
— , and K. I. Hodges, 2002: New perspectives on the Northern Hemisphere winter storm tracks. J. Atmos. Sci., 59, 10411061.

$\longrightarrow$, and 2005: A new perspective on the Southern Hemisphere storm tracks. J. Climate, 18, 4108-4129.

_ I. I. James, and G. H. White, 1983: The shape, propagation and mean-flow interaction of large-scale weather systems. J. Atmos. Sci., 40, 1595-1612.

— M. E. McIntyre, and A. W. Robertson, 1985: On the use and significance of isentropic potential vorticity maps. Quart. J. Roy. Meteor. Soc., 111, 877-946.

Levitus, S., and Coauthors, 1998: Introduction. Vol. 1, World Ocean Atlas 1998, NOAA Atlas NESDIS 18, 346 pp.

Medeiros, B., B. Stevens, I. M. Held, M. Zhao, D. L. Williamson, J. G. Olson, and C. S. Bretherton, 2008: Aquaplanets, climate sensitivity, and low clouds. J. Climate, 21, 4974-4991.

Nigam, S., I. M. Held, and S. W. Lyons, 1988: Linear simulation of the stationary eddies in a GCM. Part II: The "mountain" model. J. Atmos. Sci., 45, 1433-1452.

Orlanski, I., 2005: A new look at the Pacific storm track variability: Sensitivity to tropical SSTs and to upstream seeding. J. Atmos. Sci., 62, 1367-1390.

Seager, R., D. S. Battisti, J. Yin, N. Gordon, N. Naik, A. C. Clement, and M. A. Cane, 2002: Is the Gulf Stream responsible for Europe's mild winters? Quart. J. Roy. Meteor. Soc., 128, 2563-2586.

Sinha, B., and R. S. Smith, 2002: Development of a fast coupled general circulation model (FORTE) for climate studies, implemented using the Oasis coupler. National Oceanography Centre Southampton Tech. Rep. 81, 67 pp.

Smith, R. S., 2004: Ocean circulation and climate dynamics under idealised continental configurations in a coupled oceanatmosphere model. Ph.D. thesis, University of Southampton, 199 pp.

Stainforth, D. A., and Coauthors, 2005: Uncertainty in predictions of the climate response to rising levels of greenhouse gases. Nature, 433, 403-406.

Webb, D. J., 1996: An ocean model code for array processor computers. Comput. Geosci., 22, 569-578.

Winton, M., 2003: On the climatic impact of ocean circulation. J. Climate, 16, 2875-2889. 